\title{
Advanced Control of Grid Interfacing Inverter
}

\author{
Mr. Prince A Basheer ${ }^{1}$, Mr. Rahul Charles C M⿻ ${ }^{2}$, Ms. Anju Jacob ${ }^{3}$ \\ M. Tech Graduate in Power System and Control, University of Kerala, India ${ }^{1}$ \\ Assistant Professor, Dept. of EEE, College of Engineering Thalassery, Kerala, India ${ }^{2}$ \\ Assistant Professor, Dept. of EEE, UKF College of Engineering and Technology, Kerala, India ${ }^{3}$
}

\begin{abstract}
Distributed Power generation Systems (DPGSs) integrate different power plants in to a unit. DPGSs based on renewable energy sources experience a large development worldwide. The excessive use of power electronics and nonlinear loads lead to power quality problems. Effects of poor power quality like sag, swell, distortion in waveform, harmonics, reactive power generation has affected both grid as well as utility sectors. The control of distributed generation systems should be improved to meet the requirements for grid interconnection. In this thesis, Photo Voltaic (PV) panel, Fuel Stack \& Wind Energy system are integrated to the three phase four wire distribution system. Renewable energy resources (RES) are connected to the grid through a grid interfacing inverter for power quality improvement. Here the control is done by the grid interfacing inverter using PI controller and PWM technique. The grid interfacing inverter can act as an active shunt filter where it can transfer active power to the grid and can mitigate the load current harmonics and supply the load reactive power demand. The source side power factor is improved and voltage sag is eliminated. Total Harmonic Distortion of the grid connected system is analysed. The analysis is used to predict the behaviour of grid connected distributed power generation systems.
\end{abstract}

Index Terms: Distributed Generation (DG), Pulse Width Modulation (PWM), Point of Common Coupling (PCC), Power Quality (PQ). Renewable Energy Sources (RES).

\section{INTRODUCTION}

Electricity demand is increasing day by day and fossil fuel is the main energy supplier of the worldwide economy, but it creates a lot of environmental problems like air pollution, acid rain, global warming etc. which make the mankind to look for alternative resources in power generation. Moreover, the day-by-day increase in usage of such fossil fuels, can create heavy shortage of such energy sources. The necessity of producing more energy which is clean and safe can be met with renewable sources eg. Sun, Wind etc. Such energy production can be of low cost and easy compared to that from fossil fuel.

Distributed Generation is the integration of renewable energy sources at the distribution level. Grid interconnection of such distributed sources can cause power quality problems. Power quality problem consist of harmonics, reactive power demand and power factor. The DG systems are required to give safe, efficient and best power quality to the connected grid. Distributed system require new strategies for the operation and management of the electricity grid in order to maintain the powersupply reliability and quality. The power-electronic technology plays an important role in distributed generation and in integration of renewable energy sources into the electrical grid and make it reliable.

Power electronics has undergone a fast evolution, because of the development [1],[2] of fast semiconductor switches that are capable of switching quickly. Sinusoidal waveform of AC voltage is highly distorted by current due to nonlinear load at common point of coupling (PCC). Due to this other load on same grid systems are affected. This creates unbalancing effect on transmission and generation side. For harmonic mitigation passive filters were used traditionally, but due to certain drawbacks of resonance due to matching with line impedance it can compensate only single harmonic at a time and bulky in weight, so they are not much in use. With development of semiconductor devices active harmonic filters with different current control strategies are extensively used.

Filters formed with active elements are known as active filters. Since no inductors are used, the circuit is more compact and less heavy. Its input impedance is high and the output impedance is low, allowing to drive low impedance loads at the output. Here in this paper the features of active filter is added to the conventional inverter without any hardware cost. Shunt active filter is cost effective for low to medium industrial load.There are different current control methods used in active filters. Here direct control method is used for the PWM generation.

The inverter [3] is thus able to do the transfer of active power transferred from renewable energy source and can provide the reactive power support and the harmonic compensation. Here three different renewable sources are taken. The PQ parameters at PCC can be improved by this method without additional cost. In proposed scheme PWM voltage source Inverter is selected. Output of the Inverter is near to sinusoidal. Here for the control, voltage in the rotating abc axis is transformed to stationary dq axis and later it is used to obtain modulating signal for pulse width modulation. Different components like DC link capacitor, PLL, V-I measurement blocks etc. are used at different stages. Here for power quality analysis parameters like harmonics, reactive power, and power factor are mainly analysed at different loads. 
INTERNATIONAL JOURNAL OF INNOVATIVE RESEARCH IN ELECTRICAL, ELECTRONICS, INSTRUMENTATION AND CONTROL ENGINEERING Vol. 3, Issue 11, November 2015

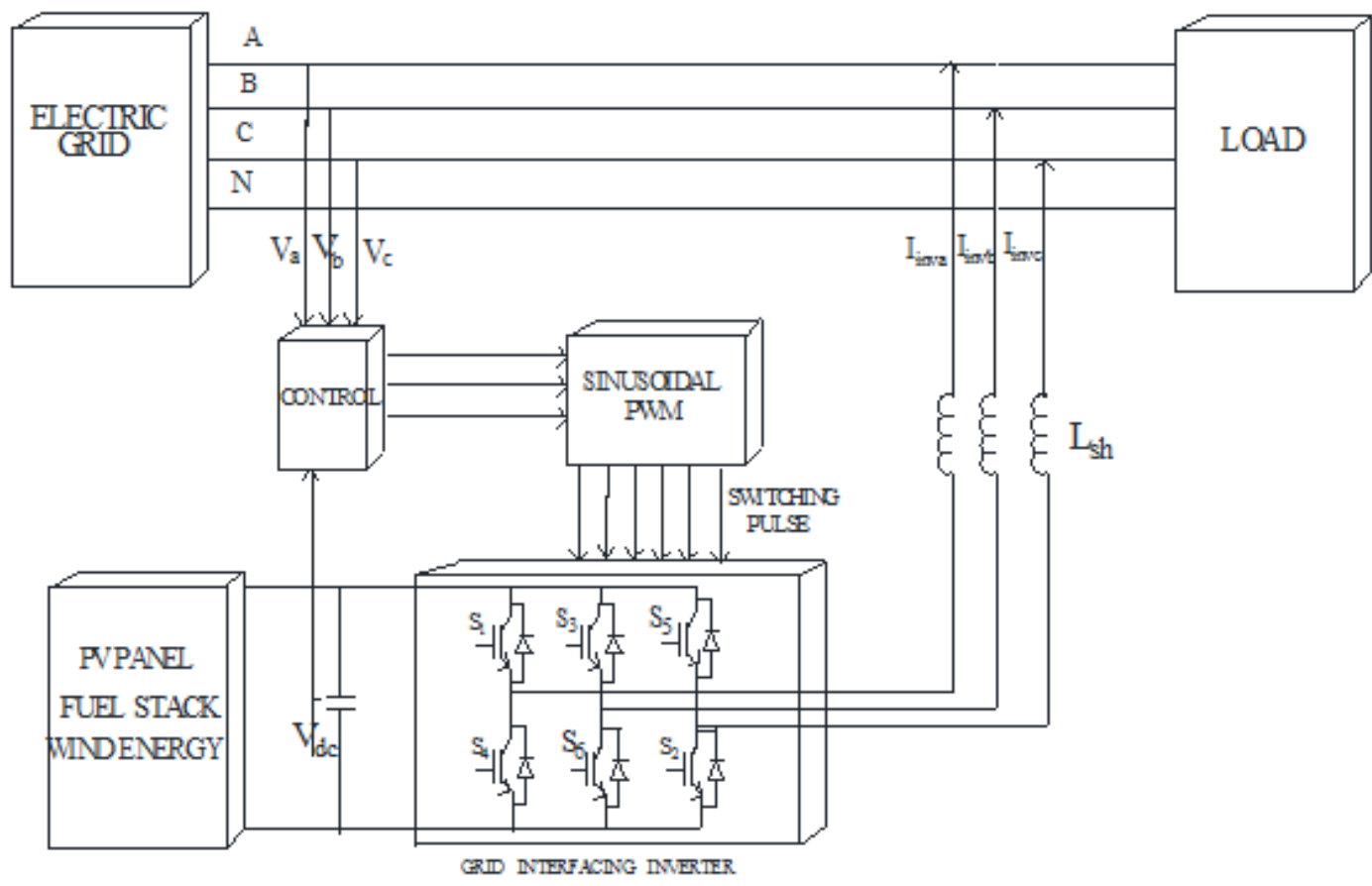

Fig.1.Schematic of proposed renewable based distributed generation system

\section{SYSTEM DESCRIPTION}

The proposed system consist of 3 phase 4 wire grid system incorporated with Photovoltaic system, Fuel stack and Wind energy system connected through a grid interfacing inverter as shown in Fig.1.The key element of a DG system is the [4] voltage source inverter as it interfaces the renewable energy source to the grid and delivers the generated power. The inverter is functioned as per the output from Sinusoidal PWM. Here the photovoltaic energy sources and Fuel stack generate power at variable $\mathrm{dc}$ voltage, while the variable speed wind turbines generate power at different ac voltage.

Thus, the power generated from these renewable sources needs power controlling (i.e., $\mathrm{dc} / \mathrm{dc}$ or $\mathrm{ac} / \mathrm{dc}$ ) before connecting on dc-link. The dc-capacitor connected, decouples the renewable source from grid and takes independent conditioning of converters on both sides of dc-link. The simulation diagram of proposed system is shown in Fig.4. The renewable sources are connected parallel to the DC link capacitor and arranged at an equal voltage to obtain synchronism.

The Fig.2 show the Fuel stack combined with Boost converter. Fuel cell is a device which through a chemical reaction of positively charged hydrogen ions and oxygen, converts the chemical energy from a fuel into electricity A single fuel cell give a voltage of about $1 \mathrm{~V}$ or higher only, so a combination of cells are used. The stack's final output voltage will depend on the number of cells and the available current will be proportional of the total surface area of the cells. Marginal output from the Fuel stack is used to get boosted. In a boost converter inductor charged to the rated value, when switch is on. When the switch is off it is discharged to the output side. The triggering pulse to the boost converter is given from the circuit itself.

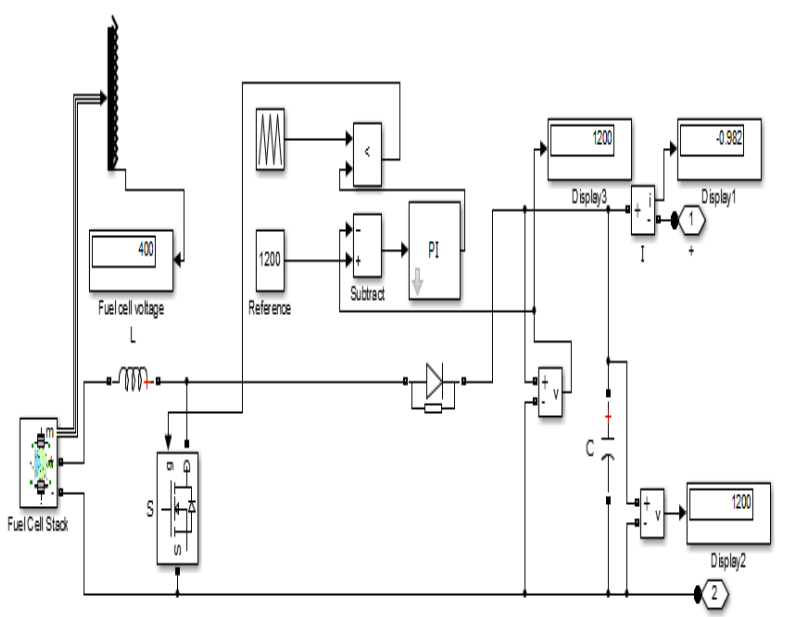

Fig.2. Fuel stack combined with Boost converter

Here an output of $1200 \mathrm{~V}$ can be obtained and the connection of Fuel Stack system to the DC link can be done effectively.

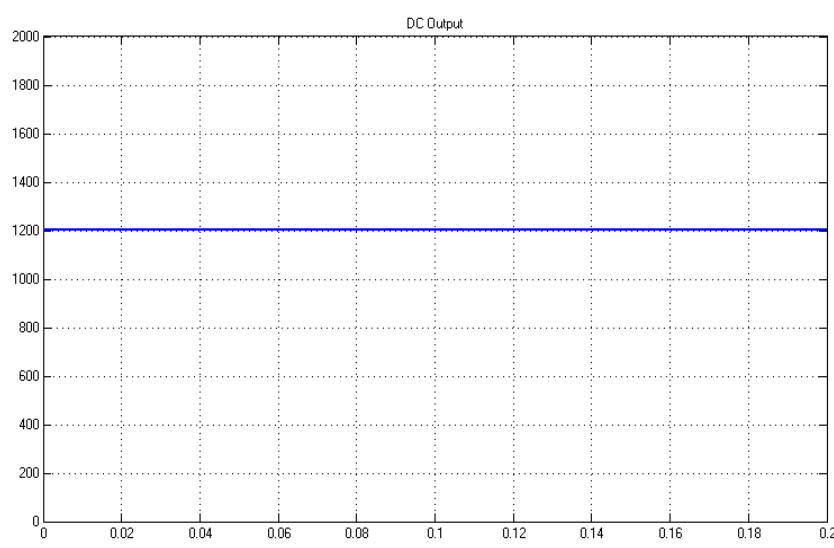

Fig.3. Output from the Fuel stack with Boost converter 


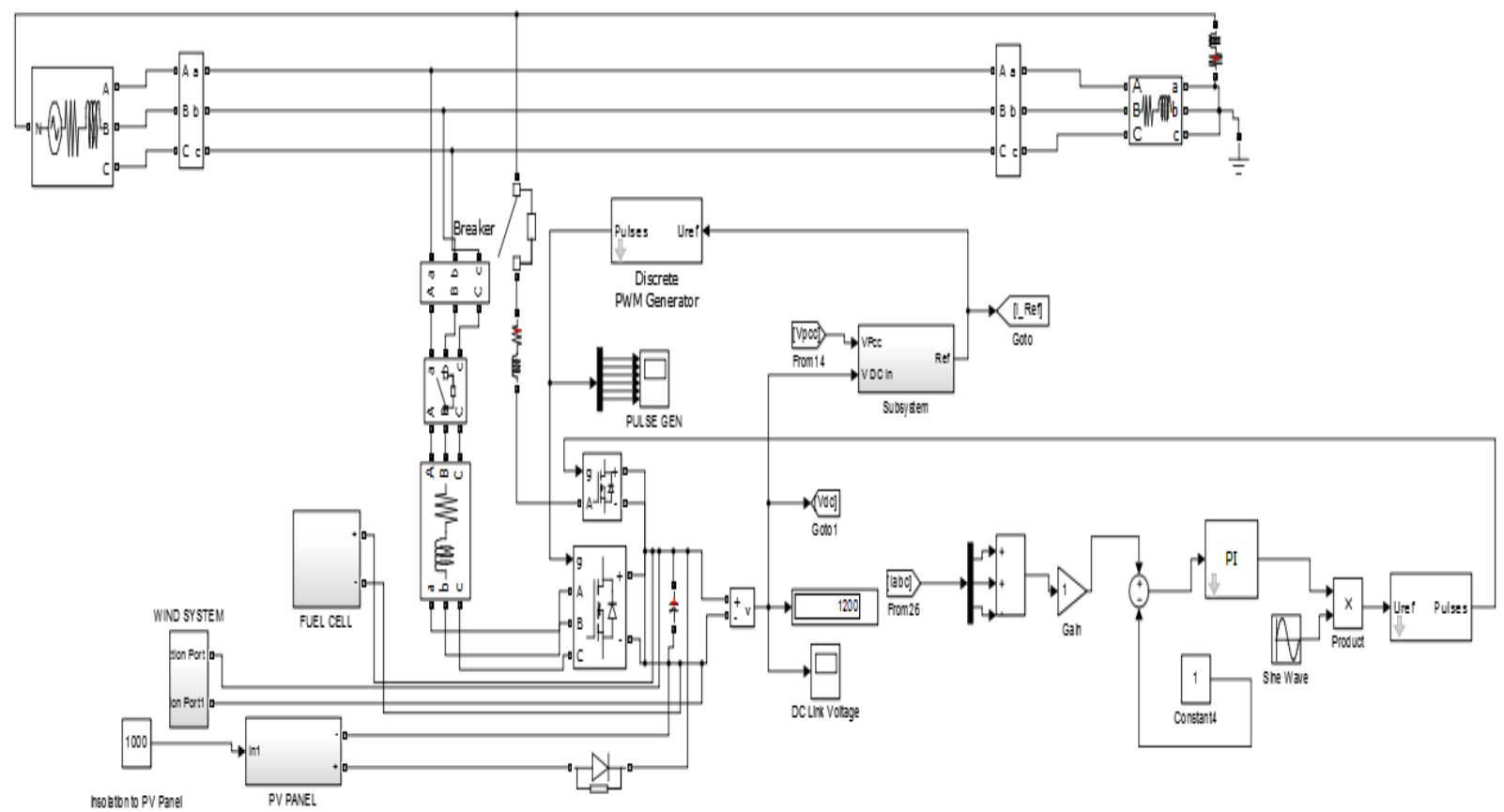

Fig.4. Simulation diagram of proposed system

\section{A. Power Control Operation}

Due to the intermittent nature of RES [5],[6], nature of the developed power is variable. The dc-link takes an important role in transferring this power from renewable energy source to the electrical grid. RES are represented as current sources connected to the dc-link of a gridinterfacing inverter. Fig.5 shows the equivalent representation of transfer of power from the renewable energy resources to the grid via the dc-link. The current injected by renewable in to dc-link at voltage level $V_{d c}$ can be given as

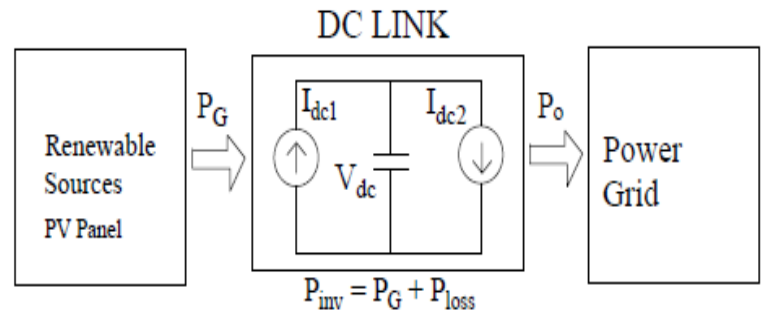

Fig.5. DC Link equivalent circuit

$$
I_{d c 1}=\frac{P_{R E S}}{V_{d c}}
$$

$\mathrm{P}_{\mathrm{RES}}$ is the power generated from RES. The current flow on the opposite side is taken as,

$$
I_{d c 2}=\frac{P_{i n v}}{V_{d c}}=\frac{P_{G}+P_{\text {Loss }}}{V_{d c}}
$$

Where $\mathrm{P}_{\text {inv }}, \mathrm{P}_{\mathrm{G}}$ and $\mathrm{P}_{\text {Loss }}$ are power obtained from the inverted side, active power supplied to the grid and the loss of the inverter.

\section{B. Control of Grid Interfacing Inverter}

While analysing the power management operation, the inverter is efficiently controlled in such a way that it can draw or supply fundamental active power [7] from or to the grid. If the load connected to the system is non-linear or unbalanced or the combination of these two, the given control scheme can compensate the harmonics, unbalance, and neutral current. The duty ratio of inverter switches are changed in a cycle in such a way, that the combination of the load appers as balanced resistive load to grid.The controlling of dc link voltage carries the information regarding the exchange of real power among the renewable source and grid.

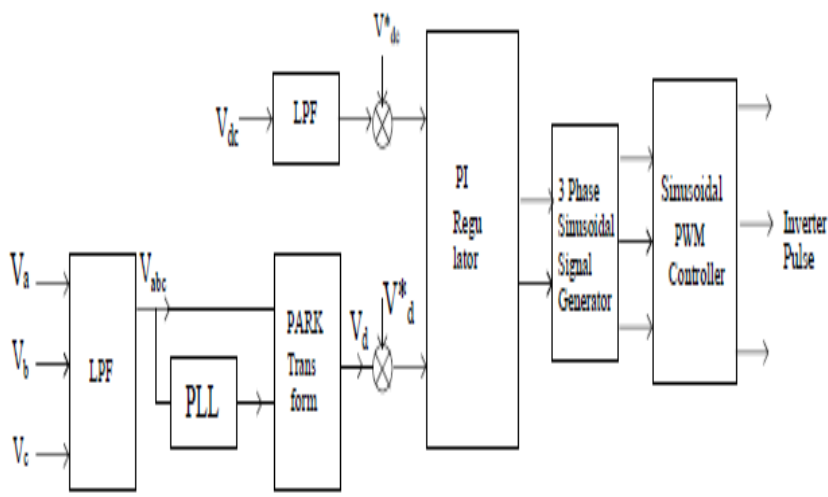

Fig.6. Block diagram representation of the inverter control

Block diagram representation of the inverter control is shown in Fig.6. The actual 3 phase voltage is sensed and passed through the second order LPF to eliminate the presence of ripples on the grid voltage. The next step is the phase locked loop which sense the grid synchronising angle to connect the inverter to the grid system. The grid synchronising angle along with phase voltage undergo the Park's transformation to become dq0 parameters.

Thus obtained d component is compared with reference value and passed to a PI regulator to obtain the reactive component. In a similar way, the real dc voltage obtained from dc link is compared is with a reference value and passed to a PI regulator to obtain the real component. 


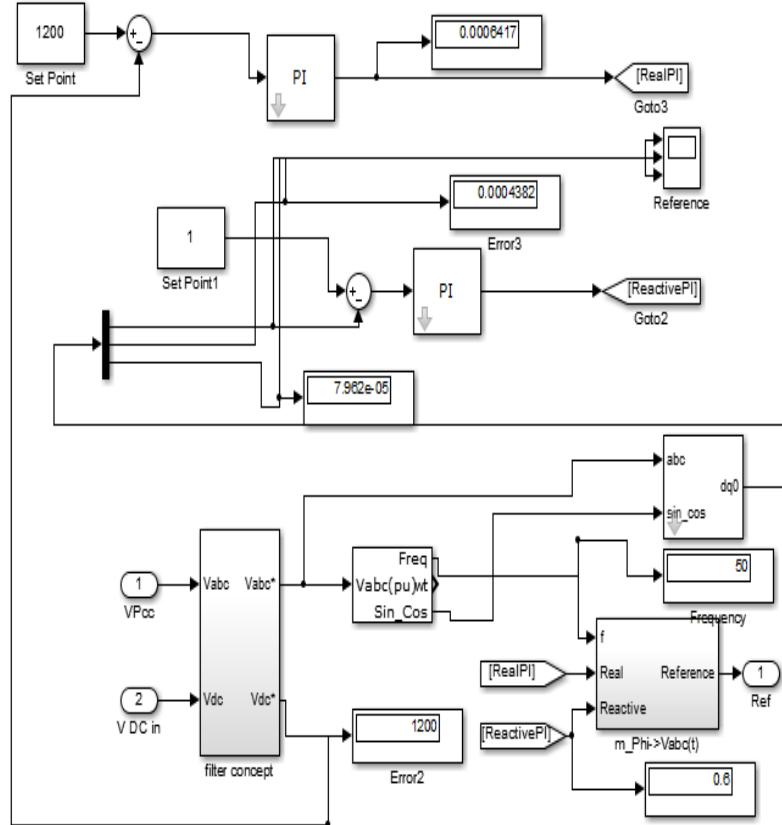

Fig.7 Simulink model of proposed circuit

The reactive component is taken as $\mathrm{V}_{\mathrm{m}}$ which is the magnitude of sinusoidal modulation signal where as the real component is taken as $\theta$. These real and reactive component are arranged as given in the Fig.8 to provide the three phase sinusoidal modulation signal.

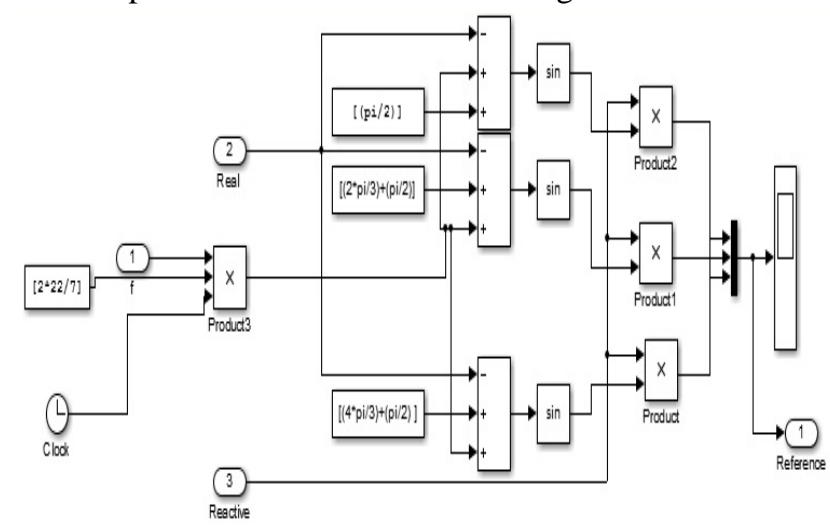

Fig.8.Sinusoidal modulation signal formation

The output voltage obtained can be represented as $\mathrm{V}_{1}, \mathrm{~V}_{2}, \mathrm{~V}_{3}$, and they are obtained as

$$
\begin{aligned}
& V_{1}=V_{m} \operatorname{Sin}(w t+90-\theta) \\
& V_{2}=V_{m} \operatorname{Sin}(w t+(120+90)-\theta) \\
& V_{3}=V_{m} \operatorname{Sin}(w t+(240+90)-\theta)
\end{aligned}
$$

The 3 phase voltage $\mathrm{V}_{1}, \mathrm{~V}_{2}, \mathrm{~V}_{3}$ are obtained and they are at a phase difference of 120.This signal is compared with a carrier signal which is a triangular wave and pulse is obtained and The triggering pulse thus formed control the switching operation.

\section{SIMULATION RESULTS}

To verify the proposed control technique to achieve multiobjectives for grid interfaced DG systems [8],[9] connected to a 3-phase 4-wire network, an extensive simulation study is carried out using MATLAB/Simulink as shown in Fig.4.

The 4-leg current controlled voltage source inverter is used to achieve balanced sinusoidal grid currents at unity power factor (UPF) irrespective of highly unbalanced nonlinear load. A RES with variable output power is connected on the dc-link of grid-interfacing inverter. A nonlinear load, whose unbalance, harmonics, and reactive power need to be compensated, is connected on PCC. The waveforms of (a) grid voltages $\left(\mathrm{V}_{\mathrm{a}}, \mathrm{V}_{\mathrm{b}}, \mathrm{V}_{\mathrm{c}}\right)$ (b) grid currents $\left(\mathrm{I}_{\mathrm{a}}, \mathrm{I}_{\mathrm{b}}, \mathrm{I}_{\mathrm{c}}\right)$ (c) load currents $\left(\mathrm{I}_{\mathrm{la}}, \mathrm{I}_{\mathrm{lb}}, \mathrm{I}_{\mathrm{lc}}\right)$ (d) inverter currents $\left(\mathrm{I}_{\text {inva }}, \mathrm{I}_{\text {invb }}, \mathrm{I}_{\text {invc }}\right)$ are shown in Fig. 9.

The corresponding active-reactive powers of grid $\left(\mathrm{P}_{\text {grid }}, \mathrm{Q}_{\text {grid }}\right)$, load $\left(\mathrm{P}_{\text {load }}, \mathrm{Q}_{\text {load }}\right)$ and inverter $\left(\mathrm{P}_{\text {inv }}, \mathrm{Q}_{\text {inv }}\right)$ are shown in Fig. 12. The power factor, harmonics etc. of the system should with in sufficient margin even at the case of any load. Power quality is defined as any power problem manifested in voltage, current, or frequency deviations that results in failure or disoperation of customer equipment. Here in the simulation results such quantities are studied.

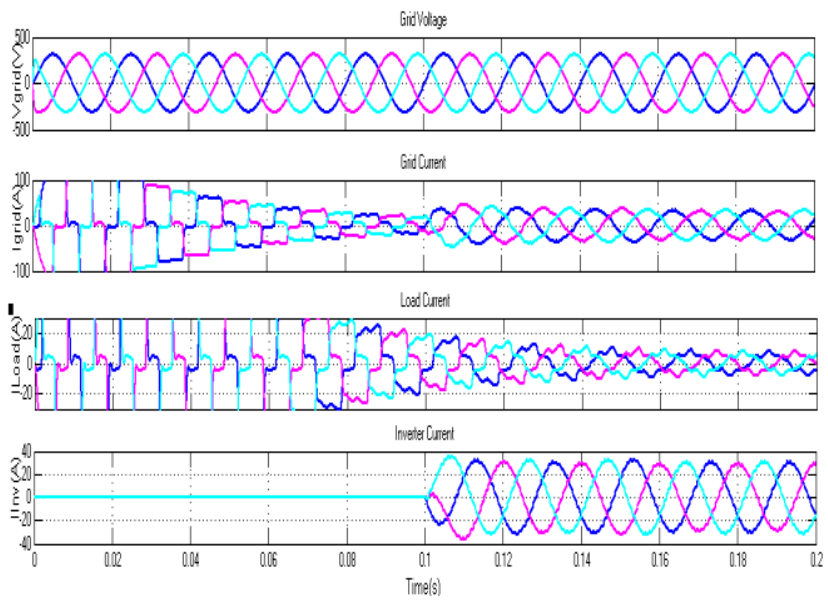

Fig.9 Simulation results (a) Grid voltage (b) Grid current(c) Load current (e) Inverter current

The Fig.9 shows the function of the proposed system when a nonlinear load is connected to the system. A nonlinear load in a power system is characterized by the introduction of switching actions and consequent current interruptions. Nonlinear loads can generate harmonic currents and these loads are of different types like computers, fax machines, printers, PLCs, refrigerators, TVs and electronic lighting ballasts. Personal computers act as nonlinear loads since they incorporate switched-mode power supplies. Here as explained in the previous sections DG system with its control scheme act as a filter. Initially the grid interfacing inverter is not connected to the system. Hence the load power demand is totally supplied by the grid alone.

Therefore, before time $.1 \mathrm{~s}$, the grid current profile is identical to the load current profile as of Fig.9(a). At .1s, the grid-interfacing inverter is connected to the network. Here inverter start to supply power to the grid system. At this instant the inverter starts injecting the current in such a way that the profile of grid current starts changing from under rated to a rated value and at the same time voltage at PCC remains rated. 


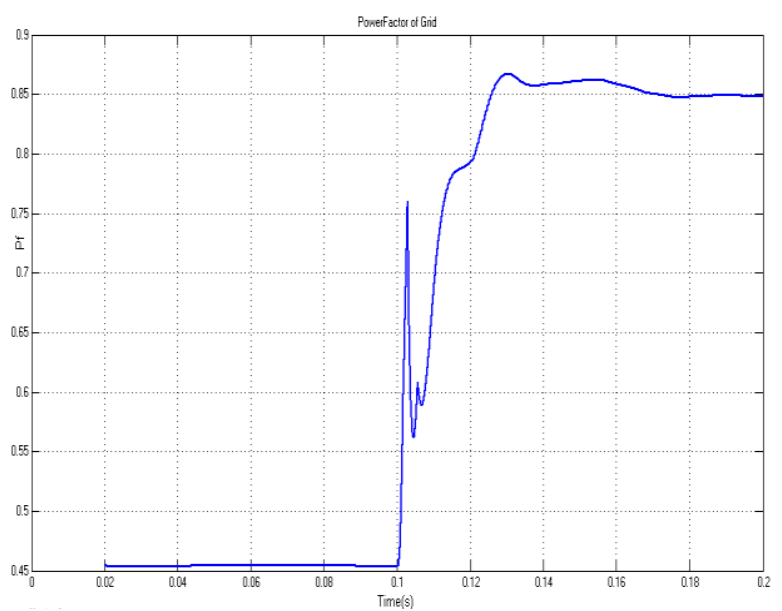

Fig.10. Power factor compensation

The Fig.10 shows the power factor compensation of the system. Initially before the connection of the DG system to the grid only a low pf of .53 is obtained because of the nonlinear load. But as the inverter is triggered at time $\mathrm{t}=$ $.1 \mathrm{~s}$, the pf shows rising from the initial value as explained from the previous section to attain the UPF. The system consist of a DC link capacitor it is the function of the DC link capacitor to provide the pf correction by injecting real and reactive power. When inverter is connected to the grid, the real and reactive component of power is given to the grid, by means of this DC link capacitor. If renewable energy sources are not present then the capacitor supply only the reactive power. In order to charge the capacitor, power is taken from the grid. After it is fully charged no other power is taken. Hence the reactive power is maintained. At .1s DG system is also available so that it can compensate both active and reactive power. Since the capacitor provide a leading current during the injection, the power factor of the system got improved. Fig. 11 shows the harmonic analysis of the system. Fundamental component give as 31.19 . At .1s filter concept of inverter is utilized, before that source follow the load current but after the time $.1 \mathrm{~s}$, grid control action occurs and hence the THD of the system is reduced to $4.88 \%$.

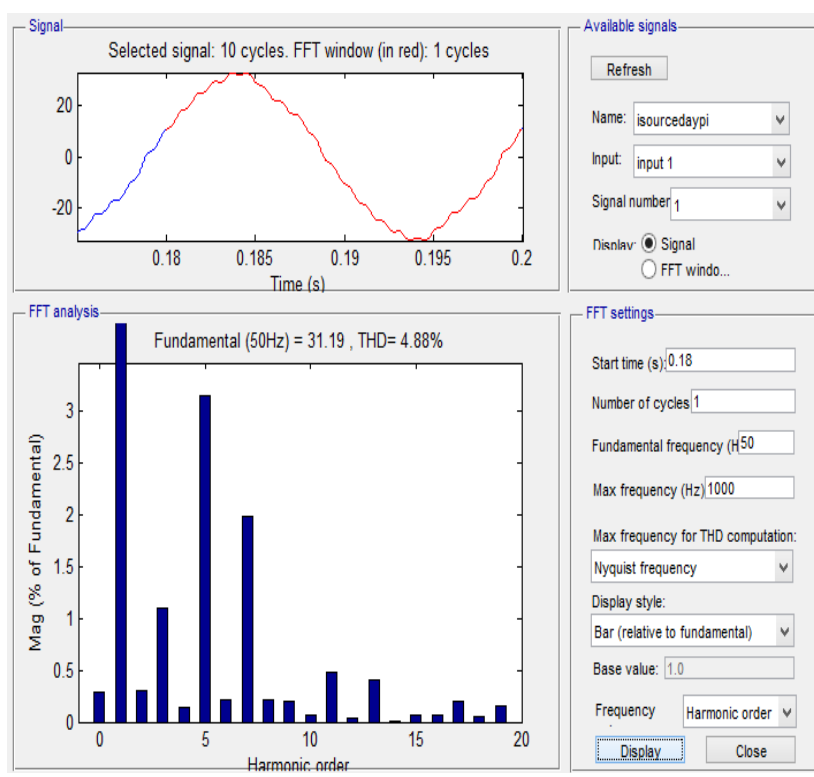

Fig.11.Harmonics analysis of the system
At $\mathrm{t}=.1 \mathrm{~s}$, the inverter starts injecting active power generated from RES.More over the grid interfacing inverter also supplies the load reactive power demand locally. From the Fig.12 it is clear that the increase in the requirement of reactive power is sufficiently provided by the inveter itself. Since the generated power is more than the load power demand, the additional power is fed back to the grid. The grid power $\mathrm{P}$ from Generator after .1s suggests that the grid is now receiving the power from RES. Once the inverter is in operation the grid only supplies/receives fundamental active power. Hence the Q from Generator become zero after the starting of inverter.

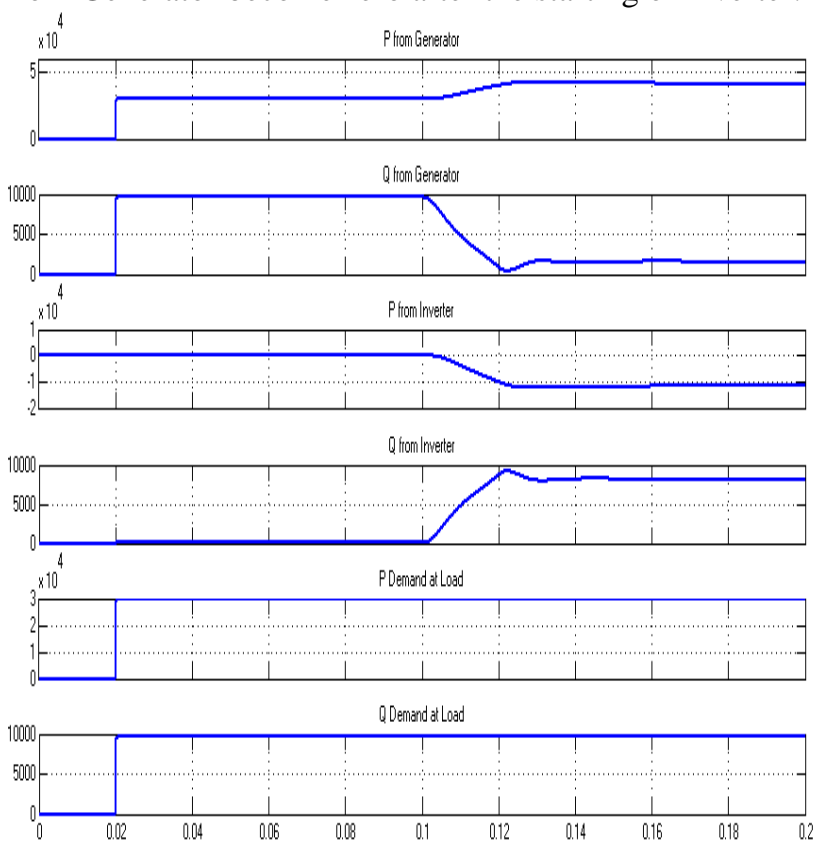

Fig.12.Simulation results (a) P Grid (b) Q Grid (c) P Inverter (d) Q Inverter (e) P Load (f) Q Load

Hence from the simulation results it is clear that the gridinterfacing inverter can be easily designed to compensate the load reactive power and current harmonics along with the active power injection from RES. This makes the grid to supply and receive sinusoidal and balanced power nearly UPF.

\section{CONCLUSION}

This thesis has presented an advanced control of an existing grid interfacing inverter to improve the power quality at PCC for a 3-phase 4-wire DG system. It is clear that the grid-interfacing inverter can be effectively used for power conditioning without affecting its normal operation of real power transfer. Distributed power generation systems used for power transmission are PV panel, Fuel stack and Wind energy system. They are connected to inverter by means of a dc link capacitor. The grid-interfacing inverter with the proposed technique can be used to inject real power generated from RES to the grid, and can operate as a shunt Active Power Filter (APF). This approach thus eliminates the need for additional power conditioning equipment to improve the quality of power at PCC. It should be possible to develop the power-electronic interface to optimize the energy conversion, transmission and reactive power, to minimize 
harmonic distortion, to achieve at a high efficiency over a wide power range, and to have a high reliability and security. The new power-electronic technology plays a very important role in the integration of renewable energy sources into the grid. Here the control is done by the grid interfacing inverter using PI controller and PWM technique. Extensive MATLAB/Simulink simulation results have validated the proposed approach It is further demonstrated that the PQ enhancement can be achieved under different scenarios. The current unbalance, current harmonics and load reactive power, due to linear, unbalanced and non-linear load, connected to the PCC, are compensated effectively such that the grid side currents are always maintained as balanced and sinusoidal at unity power factor. Using the power generated from RES, the grid-interfacing inverter with the proposed control approach can fulfill the total load active and reactive power demand but can also delivers the excess generated sinusoidal active power to the grid at unity power factor.

\section{REFERENCES}

[1] M. Singh, V. Khadkikar, A. Chandra, and R. K. Varma,"Grid interconnection of renewable energy sources at the distribution level with power quality improvement features," IEEE Trans. Power Del., vol. 26, no. 1, p 307-315, Jan. 2011.

[2] B. Renders, K. De Gusseme, W. R. Ryckaert, K.Stockman, L. Vandevelde, and M. H. J. Bollen "Distributed generation for mitigating voltage dips in low-voltage distribution grids," IEEE Trans. Power. Del., vol. 23, no. 3, pp. 1581-1588, Jul. 2008

[3] F. Blaabjerg, R. Teodorescu, M. Liserre, and A. V. Timbus, "Overview of control and grid synchronization for distributed power generation systems," IEEE Trans. Ind. Electron., vol. 53, no. 5, pp. 1398-1409, Oct. 2006

[4] J. M. Carrasco, L. G. Franquelo, J. T. Bialasiewicz, E. Galván, R. C.P. Guisado, M. A. M. Prats, J. I. León, and N. M. Alfonso, "Power electronic systems for the grid integration of renewable energy sources: A survey," IEEE Trans. Ind. Electron., vol. 53, no. 4, pp. 1002-1016, Aug. 2006.

[5] P. Rodríguez, J. Pou, J. Bergas, J. I. Candela, R. P. Burgos, and D. Boroyevich, "Decoupled double synchronous reference frame PLL for power converters control," IEEE Trans. Power Electron, vol. 22, no. 2, pp. 584-592, Mar. 2007.

[6] V. Khadkikar, A. Chandra, A. O. Barry, and T. D. Nguyen "Application of UPQC to protect a sensitive load on a polluted Distribution network," in Proc. Annu. Conf. IEEE Power Eng. Soc. Gen. Meeting, 2006, pp. 867-872.

[7] J. H. R. Enslin and P. J. M. Heskes, "Harmonic interaction between a large number of distributed power inverters and the distribution network," IEEE Trans. Power Electron., vol. 19, no. 6, pp. 1586-1593, Nov. 2004.

[8] J. P. Pinto, R. Pregitzer, L. F. C. Monteiro, and J. L. Afonso, “3phase 4-wire shunt active power filter with renewable energy interface," presented at the Conf. IEEE Renewable Energy \& Power Quality, Seville ,Spain, 2007.

[9] M. Singh and A. Chandra, "Power maximization and voltage sag/swell ride-through capability of PMSG based variable speed wind energy conversion system," in Proc. IEEE 34th Annu. Conf. Indus. Electron. Soc., 2008, pp. 2206-2211.

[10] B. Renders, W. R. Ryckaert, K. De Gussemé, K. Stockman, and L.Vandevelde, "Improving the voltage dip immunity of converterconnected distributed generation units," Elsevier Renew. Energy, vol. 33, no. 5, pp. 1011-1018, May 2008. 